\title{
Fabrication of Net-Shape Functionally Graded Composites by Electrophoretic Deposition and Sintering: Modeling and Experimentation
}

\author{
E. A. Olevsky, ${ }^{\dagger}$ X. Wang, and A. Maximenko \\ Department of Mechanical Engineering, San Diego State University, San Diego, California 92182-1323
}

M. A. Meyers

Department of Mechanical and Aerospace Engineering, University of California, San Diego, California 92093-0411

\begin{abstract}
It is shown that electrophoretic deposition (EPD) sintering is a technological sequence that is capable of producing net-shape bulk functionally graded materials (FGM). By controlling the shape of the deposition electrode, components of complex shapes can be obtained. To enable sintering net-shape capabilities, a novel optimization algorithm and procedure for the fabrication of net-shape functionally graded composites by EPD and sintering has been developed. The initial shape of the green specimen produced by EPD is designed in such a way that the required final shape is achieved after sintering-imposed distortions. The optimization is based on a special innovative iteration procedure that is derived from the solution of the inverse sintering problem: the sintering process is modeled in the "backward movie" regime using the continuum theory of sintering incorporated into a finite-element code. The experiments verifying the modeling approach include the synthesis by EPD of $\mathrm{Al}_{2} \mathrm{O}_{3} / \mathrm{ZrO}_{2} 3-\mathrm{D}$ (FGM) structures. In order to consolidate green parts shaped by EPD, post-EPD sintering is used. The fabricated deposits are characterized by optical and scanning electron microscopy. The experimentally observed shape change of the FGM specimen obtained by EPD and sintering is compared with theoretical predictions.
\end{abstract}

\section{Introduction: Concept of Net-Shape Functionally Graded Material (FGM) Fabrication}

$\mathrm{L}$ ET us assume that a certain final shape of a powder sample should be obtained after sintering. For a functionally structured (e.g., graded) "green" (presintering) component, the microscopic structure is spatially nonuniform, which should cause differential shrinkage leading to shape distortions after sintering. This paper describes an experimental-theoretical optimization technique that enables the determination of the initial shape of a green specimen rendering the required final shape after sintering. This approach includes the solution of the inverse sintering problem based on the detailed analysis of the evolution of macroscopically inhomogeneous material structures during sintering. If the kinetics of sintering is known, then the prediction of the initial shape and of the structure of a green body is conducted through an iteration procedure based on the idea of the "backward movie," where the directions of all physical processes during modeling are changed to the opposite ones.

J. Rodel—contributing editor

Supported by the National Science Foundation, Division of Civil and Mechanical Systems (Grant CMS-030115), Division of Materials Research (Grants DMR-0315290 and DMR-0313346), and Division of Manufacturing and Industrial Innovations (Grant DMI0354857).

Author to whom correspondence should be addressed. e-mail: eolevsky@mail.sdsu.edu
For heterogeneous materials, the solution of the inverse sintering problem indubitably leads to the request for some complex-shape functionally structured (in particular, graded) initial green specimen. How can such a specimen be produced?

A green presintering specimens assembly approach can be based on the electrophoretic deposition (EPD): assembling powder particles from suspensions under the influence of an electric field. As a result of the assembly, 3-D net-shape components with presupposed internal structures can be fabricated. Various ceramics and metals have been deposited by EPD from aqueous and organic suspensions. ${ }^{1}$ In EPD, the suspension concentration can be changed continuously, and so it is possible to synthesize functionally graded materials. Several systems of FGM have been fabricated such as $\mathrm{Al}_{2} \mathrm{O}_{3} / \mathrm{ZrO}_{2}$, WC/Co, etc. ${ }^{2-8}$ In the past, EPD was mainly used for the formation of coatings. The shaping of 3-D free-standing objects is an additional promising application area for this technology. In general, during EPD, the assembly process is controlled through the application of specially shaped electrodes, through the manipulation of the electric field and of the composition of a suspension. Clearly, the most feasible objective of this control is the adjustment of the material structure of an assembled component in accordance with its future applications.

The as-deposited green sample has a low strength and has to be densified further by thermal processing such as hot isostatic pressing, free sintering, etc. A combination of the EPD and sintering is used in this research for the verification of the model predictions.

Based on the formulated concept, the logistics of our technological approach can be represented in the form of the following "problem $\rightarrow$ solution" sequence:

(1) Net-shape manufacturing by sintering $\rightarrow$ inverse sintering problem solution: green specimen with a special shape and with a special (composite) structure.

(2) Fabrication of a special shape functionally structured (graded) green specimen $\rightarrow$ EPD.

Both EPD and sintering-related "backward predictions" are absolutely essential for the practical implementation of the netshape assembly. For these processing approaches, the modeling is not just a desirable appendix aimed at the clarification of physical processes behind the technology. In both the electrophoretic assembly of 3-D bodies and coatings and in net-shape sintering, modeling is an essential part of the fabrication approach.

The paper is organized as follows:

Sections II(1)-(3) include the description of a constitutive model of sintering of powder mixtures, which is utilized in the present work for the analysis of the sintering of functionally graded structures. Section II(4) describes a finite-element implementation of the developed constitutive model of sintering of powder mixtures. Section II (5) introduces algorithms for the 
solution of the "inverse" problem of sintering - optimization of the initial shape of a powder specimen rendering the required final shape after sintering. Section III(1) describes the equipment, materials, and procedures of EPD of alumina-zirconia-graded powder composites. Section III(2) includes both the description of dilatometry tests necessary for the determination of the sintering constitutive parameters of alumina-zirconia powder mixtures and the results of the sintering of functionally graded alumina-zirconia cylindrical specimens. Section III (3) is dedicated to the experimental implementation of the EPD-sintering model-based net-shape optimization.

\section{Modeling of Sintering of FGM}

\section{(1) Basics of Continuum Theory of Sintering}

The main constitutive relationship of the linear-viscous version of the continuum theory of sintering ${ }^{9-19}$ is represented below:

$$
\sigma_{i j}=2 \eta_{0}\left[\phi \dot{\varepsilon}_{i j}+\left(\psi-\frac{1}{3} \phi\right) \dot{e} \delta_{i j}\right]+P_{\mathrm{L}}
$$

where $\varphi$ and $\psi$ are the normalized shear and bulk viscosity moduli, which depend on porosity $\theta$ and other structure parameters such as grain (particle) size, relative interparticle neck radius, etc.; $\eta_{0}$ is the shear viscosity of the fully dense porous body skeleton; $\delta_{i j}$ is a Kronecker symbol; and $\dot{e}$ is the first invariant of the strain rate tensor. Physically, $\dot{e}$ represents the volume change rate of a porous body. $P_{\mathrm{L}}$ is an effective Laplace stress (sintering stress), which depends on the local sintering stress $P_{\mathrm{L} 0}$, porosity, and various pore structure parameters such as the relative interparticle neck radius. The porosity $\theta$ is the ratio of the pore volume to the volume of a porous body.

Formulation (1) can be used for the description of a wide range of processes of powder treatment. Parameter $\sigma_{i j}$ corresponds to the macroscopic stress applied to a representative volume element. The first term of the right-hand part characterizes the porous material's resistance, and the second term corresponds to the influence of capillary (sintering) stresses. In the case where the macroscopic stress $\sigma_{i j}$ is equal to zero, Eq. (1) describes free sintering. In the case when the effective sintering stress $P_{\mathrm{L}}$ is equal to zero, Eq. (1) describes treatment by pressure without sintering. In general, Eq. (1) describes sintering under pressure.

It should be noted that existing model concepts and numerical codes, in particular those based upon the continuum theory of sintering, depend on the accurate determination of the constitutive parameters such as the bulk and shear moduli $(\psi$ and $\varphi)$ and the sintering stress $P_{\mathrm{L}}$.

For free sintering, the external applied stress is zero; thus Eq. (1) is reduced to:

$$
\dot{e}=-\frac{P_{\mathrm{L}}}{2 \eta_{0} \psi}
$$

The existing continuum theory of sintering ${ }^{13}$ provides the necessary expressions for the modeling of sintering locally homogeneous powder components. The problem of sintering of FGMs requires the development of expressions for the sintering stress $P_{\mathrm{L}}$ and the bulk and shear moduli $\psi$ and $\varphi$ taking into account locally heterogeneous structures of FGM, such as those that exist in the case of mixtures of two-component powders. The corresponding expressions for the constitutive parameters of FGM sintering are derived in Sections II(2) and (3).

\section{(2) Sintering Stress for a Two-Component Mixture of Particles}

A general formula for the sintering stress is given in McMeeking and $\mathrm{Kuhn}^{20}$ :

$$
P_{\mathrm{L}}=-\frac{1}{V \dot{e}} \int_{L_{\mathrm{p}}} \sigma_{0} m_{i} j_{i} \mathrm{~d} L
$$

where repeating indices mean summation, $V$ is the volume of the powder, $L_{\mathrm{p}}$ is the overall combination of the perimeters of all contacts between particles, $\vec{m}$ is the unit vector normal to $L_{\mathrm{p}}$ within the local plane of contact, $\vec{j}$ is the diffusion flux, $\sigma_{0}$ is the value of the normal stress on $L_{\mathrm{p}}$, and $\dot{e}$ is the specific rate of the volume change. The stress $\sigma_{0}$ can be assessed as

$$
\sigma_{0}=\alpha K
$$

where $K$ is the sum of the principal curvatures on $L_{\mathrm{p}}$, and $\alpha$ is the specific surface energy. The curvature $K$ at the edge of the neck between two equal spherical particles can be estimated $\mathrm{as}^{21}$ :

$$
K=\frac{\chi R}{x^{2}}-\frac{2}{x} \sin \frac{\omega}{2}
$$

where $\chi$ is a constant, $x$ is the neck radius, and $\omega$ is the dihedral angle. In the ensuing assessments, the contribution of the second term in the right-hand side of (5) will be considered to be negligible. For the sintering of particles with different radii, the curvature $K$ can be estimated as follows ${ }^{22}$ :

$$
K=\frac{\chi}{x^{2}} \frac{2 R_{1} R_{\mathrm{s}}}{R_{\mathrm{l}}+R_{\mathrm{s}}}
$$

where $R_{\mathrm{S}}$ and $R_{1}$ are the radii of the small and large particles, respectively.

The diffusion flux in (3) can be found through the shrinkage rate $\dot{w}^{21}$ :

$$
m_{i} j_{i}=\dot{w} x
$$

where $2 \dot{w}$ is the rate of approach of one particle toward the other. The shrinkage rate, in turn, can be evaluated through the rate of the volume change

$$
\dot{w}=\frac{1}{3} \dot{e} \frac{R_{\mathrm{l}}+R_{\mathrm{s}}}{2}
$$

After the substitution of (8), (7), and (4) into (3), the formula for the sintering stress assumes the form

$$
P_{\mathrm{L}}=-\frac{2 \pi \alpha}{3 V} \sum R_{1} R_{2}
$$

where summation has taken place over all necks between particles. Parameters $R_{1}, R_{2}$ are the radii of the particles forming a particular neck. According to (9), the sintering stress does not depend on the radii of necks between particles. For the unit volume of powder, formula (9) gives

$$
\begin{aligned}
P_{\mathrm{L}}= & -\frac{\pi \alpha \chi(1-\theta)}{3} \\
& \times\left[\frac{\phi_{\mathrm{s}}}{\frac{4}{3} \pi R_{\mathrm{s}}^{3}}\left(R_{\mathrm{s}}^{2} n_{\mathrm{ss}}+R_{\mathrm{l}} R_{\mathrm{s}} n_{\mathrm{sl}}\right)+\frac{\phi_{1}}{\frac{4}{3} \pi R_{\mathrm{l}}^{3}}\left(R_{1}^{2} n_{\mathrm{ll}}+R_{\mathrm{l}} R_{\mathrm{s}} n_{\mathrm{ls}}\right)\right]
\end{aligned}
$$

where $\phi_{1}$ and $\phi_{\mathrm{s}}$ are the volume concentrations of small and large particles, respectively; $n_{\mathrm{s} 1}$ is the coordination number of small particles in contact with large particles, $n_{\mathrm{ss}}, n_{\mathrm{ls}}$, and $n_{11}$ are defined in a similar way; and $\theta$ is the porosity. The values of the coordination numbers were taken from Suzuki and Oshima. ${ }^{23}$

The coordination number of the small particles with respect to large particle neighbors can be found in the form

$$
n_{\mathrm{sl}}=S_{\mathrm{a}} N_{\mathrm{sl}}
$$


where $S_{\mathrm{a}}$ is the so-called fractional area of large particles

$$
S_{\mathrm{a}}=\frac{\phi_{1}}{\phi_{1}+\left(R_{\mathrm{l}} / R_{\mathrm{s}}\right) \phi_{\mathrm{s}}}
$$

and $N_{\mathrm{sl}}$ is the coordination number if a small particle has contacts only with large particles

$$
N_{\mathrm{sl}}=\frac{0.5 N_{\mathrm{c}}\left(1+c_{\mathrm{sl}}\right)}{1+c_{\mathrm{sl}}-\left(c_{\mathrm{sl}}^{2}+2 c_{\mathrm{sl}}\right)^{\frac{1}{2}}}
$$

Parameter $N_{\mathrm{c}}$ is the assumed average coordination number for a packing of spheres of the same size. In the present calculations, it was taken to be equal to 6 . Parameter $c_{\mathrm{sl}}=R_{\mathrm{S}} / R_{1}$. Coordination numbers $n_{\mathrm{ss}}, n_{11}$, and $n_{\mathrm{ls}}$ can be found from formulas (11)-(13) by interchange of indices.

The final result after the substitution of the coordination numbers is as follows:

$$
\begin{aligned}
P_{\mathrm{L}}= & -\frac{\alpha \chi(1-\theta) N_{\mathrm{c}}}{4}\left\{\frac{\phi_{s} c_{\mathrm{ls}}}{R_{\mathrm{s}}\left(\phi_{1}+c_{\mathrm{ls}} \phi_{\mathrm{s}}\right)}\left[\phi_{\mathrm{s}}+\frac{\left(1-\frac{\sqrt{3}}{2}\right) \phi_{l}\left(1+c_{\mathrm{ls}}\right)}{1+c_{\mathrm{ls}}-\sqrt{1+2 c_{\mathrm{ls}}}}\right]\right. \\
& \left.+\frac{\phi_{\mathrm{l}} c_{\mathrm{sl}}}{R_{\mathrm{l}}\left(\phi_{\mathrm{s}}+c_{\mathrm{sl}} \phi_{\mathrm{l}}\right)}\left[\phi_{1}+\frac{\left(1-\frac{\sqrt{3}}{2}\right) \phi_{s}\left(1+c_{\mathrm{sl}}\right)}{1+c_{\mathrm{sl}}-\sqrt{1+2 c_{\mathrm{sl}}}}\right]\right\}
\end{aligned}
$$

where $c_{1 \mathrm{~s}}=R_{1} / R_{\mathrm{s}}$. The normalized (with respect to the sintering stress corresponding to large particles only) sintering stress $P_{\mathrm{L}} /$ $P_{\mathrm{L}}^{\mathrm{Large}}$ as a function of the volume concentrations of small and large particles for different ratios of particle sizes is given in Fig. 1. The normalized sintering stress increases with both an increase of the volume concentration of small particles and with the increase of the ratio $c_{\mathrm{ls}}=R_{1} / R_{\mathrm{S}}$ (which promotes higher coordination numbers).

\section{(3) Bulk Viscosity for a Mixture of Alumina and Zirconia}

According to the experimental results,${ }^{24}$ the average densification rate $\dot{\rho}$ during sintering of mixture of alumina and zirconia can be approximated in the following form:

$$
\dot{\rho}=A \frac{\exp \left(-Q / R_{\mathrm{g}} T\right)}{T} \frac{f(\rho)}{R_{\mathrm{p}}^{4}}
$$

where $\rho$ is the relative density of the powder $(\rho=1-\theta), A$ is a constant, $T$ is the temperature, $R_{\mathrm{g}}$ is the gas constant, $f(\rho)$ is a function of density, and $R_{\mathrm{p}}$ is the effective particle size (see Eq.

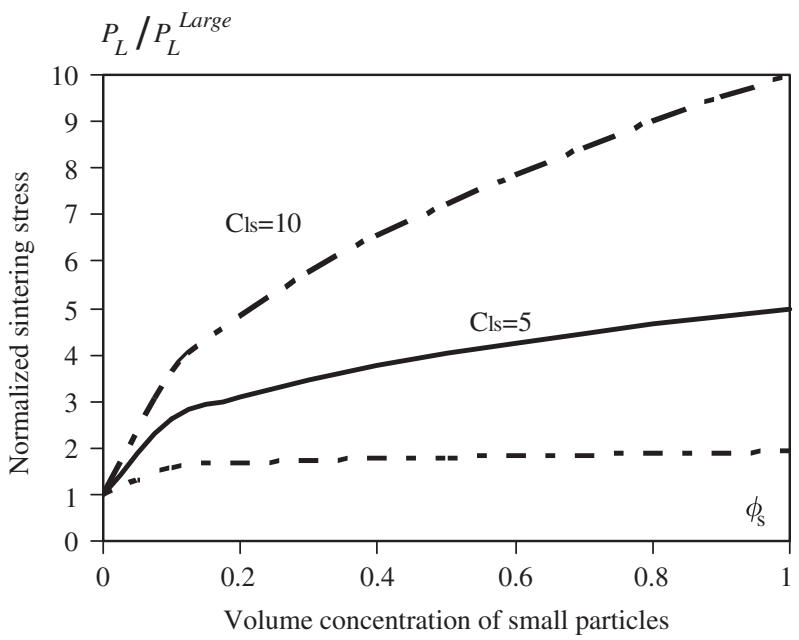

Fig. 1. Normalized sintering stress as a function of volume concentrations of small and large particles in the bimodal particle mixture.
(18)). Experimental data ${ }^{24}$ for the activation energy $Q$ in the numerical examples were approximated as

$$
Q=\left\{\begin{array}{l}
440+5200 \phi_{\mathrm{ZrO}_{2}}, \phi_{\mathrm{ZrO}_{2}}<0.05 \\
700,0.05 \leq \phi_{\mathrm{ZrO}_{2}} \leq 0.95 \mathrm{~kJ} / \text { mole } \\
615+1700\left(1-\phi_{\mathrm{ZrO}_{2}}\right), \phi_{\mathrm{ZrO}_{2}}>0.95
\end{array}\right.
$$

where $\phi_{\mathrm{ZrO}_{2}}$ is the volume fraction of zirconia. Approximation (16) has been verified by dilatometry experiments carried out for specimens produced from various mixtures of alumina and zirconia powders (see Section III $(2)(A)$ ).

The function $f(\rho)$ was taken from Olevsky ${ }^{13}$ in the form:

$$
f(\rho)=\frac{1-\rho}{\rho}
$$

According to Pan and colleagues, ${ }^{22,25}$ the sintering rate for powder compacts with particles of the same size can be transformed into a more general case of the sintering rate of powder compacts with a bi-modal particle size distribution by the introduction of an effective particle size

$$
R_{\mathrm{p}}=R_{\mathrm{l}} \kappa\left(c_{\mathrm{s}}, \phi_{\mathrm{s}}\right)
$$

where

$$
\kappa=\frac{c_{\mathrm{sl}}^{3}\left(1-\phi_{\mathrm{s}}\right)^{2}+\phi_{\mathrm{s}}\left(1-\phi_{\mathrm{s}}\right)\left(1+c_{\mathrm{sl}}\right) c_{\mathrm{sl}}+\phi_{\mathrm{s}}^{3}}{c_{\mathrm{sl}}^{3}\left(1-\phi_{\mathrm{s}}\right)^{2}+0.5 \phi_{\mathrm{s}}\left(1-\phi_{\mathrm{s}}\right)\left(1+c_{\mathrm{sl}}\right)^{2} c_{\mathrm{sl}}+\phi_{\mathrm{s}}^{2} c_{\mathrm{sl}}}
$$

Substitution of Eqs. (16)-(19) into Eq. (15) provides an assessment of the densification rate during sintering of a mixture of powders for any concentrations of constituents.

The bulk viscosity $\psi$ of a powder compact (see Eq. (2)) can be obtained as a ratio of the sintering stress and the rate of the free sintering densification.

$$
\psi=-\frac{P_{\mathrm{L}} \rho}{2 \eta_{0} \dot{\rho}}
$$

The ratio of the shear viscosity to the bulk viscosity of powder elements was taken to be equal ${ }^{13}$ to $1.5 f(\rho)$.

\section{(4) Modeling Results: Solution of Direct Problem of Sintering of FGM}

Numerical approaches for the prediction of shape distortions and density evolution of components are usually based on finite element implementations ${ }^{13,14,19,26-30}$ of continuum models of sintering. From the macroscopic point of view, shrinkage during free sintering can be treated as a linear creep of a porous body under the influence of the sintering stress ${ }^{13}$ (see Eq. (1)). If the initial shape and the composition of a powder body are known, the continuum theory of sintering can predict its final shape.

The FGM $\mathrm{Al}_{2} \mathrm{O}_{3}-\mathrm{ZrO}_{2}$ disk sintering has been modeled by the finite element code ABAQUS ${ }^{\mathrm{TM}}$ using the constitutive equations of the continuum theory of sintering modified for the case of a functionally graded medium (in accordance with the results of Sections $\mathrm{II}(2)$ and (3)). In order to ensure the correctness of the formulation and the accuracy of the finite element numerical solutions, a benchmark test has been performed using CREEP subroutine in ABAQUS ${ }^{\mathrm{TM}}$. Two models were compared: the first one used Eq. (2) to calculate the sintering strain rate; the second one used the ABAQUS ${ }^{\mathrm{TM}}$-embedded function to evaluate the strain rate. The two obtained solutions were identical. The shear $\Delta \gamma$ and the volume $\Delta e$ strain increments have been calculated by the subroutine "CREEP" in ABAQUS $^{\mathrm{TM}}$ as

$$
\Delta \gamma=\frac{\tilde{q}}{\eta_{0} \phi} \Delta t, \quad \Delta e=\frac{P+P_{\mathrm{L}}}{2 \eta_{0} \psi} \Delta t
$$

where $\tilde{q}$ is the Mises stress and $P$ is an external stress (in free sintering, $P=0)$. 
Owing to symmetry, only a quarter of the specimen is considered (see Fig. 2). Accordingly, there are two symmetry boundary conditions along two cutting planes. The disk is partitioned into four layers; each layer is assigned a material property. It is assumed that the initial porosity is the same in each layer; only the composition (in terms of alumina and zirconia concentrations) is spatially nonuniformly (linearly $15 \%-85 \%$ see Section III $(2)(B)$ ) distributed. From Eq. (18), the equivalent particle size can be determined. In the simulation, the alumina and zirconia particle sizes are taken to be 5.0 and $0.5 \mu \mathrm{m}$, respectively (in accord with the powder characteristics used in the verifying experiments - see Section III). The material parameters and temperature regime are chosen in full correspondence with the ones used in the respective experiments described in Section III.

The finite element simulation results are shown in Fig. 2. It is clear that the upper layer, which contains more zirconia, densifies faster than the bottom layer. The initial porosity of the specimen was set to $\theta=0.35$. At the end of sintering, the top layer had a porosity of 0.09 , while the bottom layer had a porosity of 0.15 . This is because the top layer has more zirconia, whose particle size is 10 times smaller than that of alumina. Smaller particles yield a higher densification rate (as highlighted by Eq. (15)).

The shape distortion during sintering is compared with the original shape. The results are shown in Fig. 3. The FEM simulation indicates that the disk warps toward the top surface, which has more zirconia particles. The reason is that the bottom layer generates larger compressive stresses than the top layer. The nonuniform stress distribution causes the warpage. The results also indicate that the disk undergoes shrinkage during
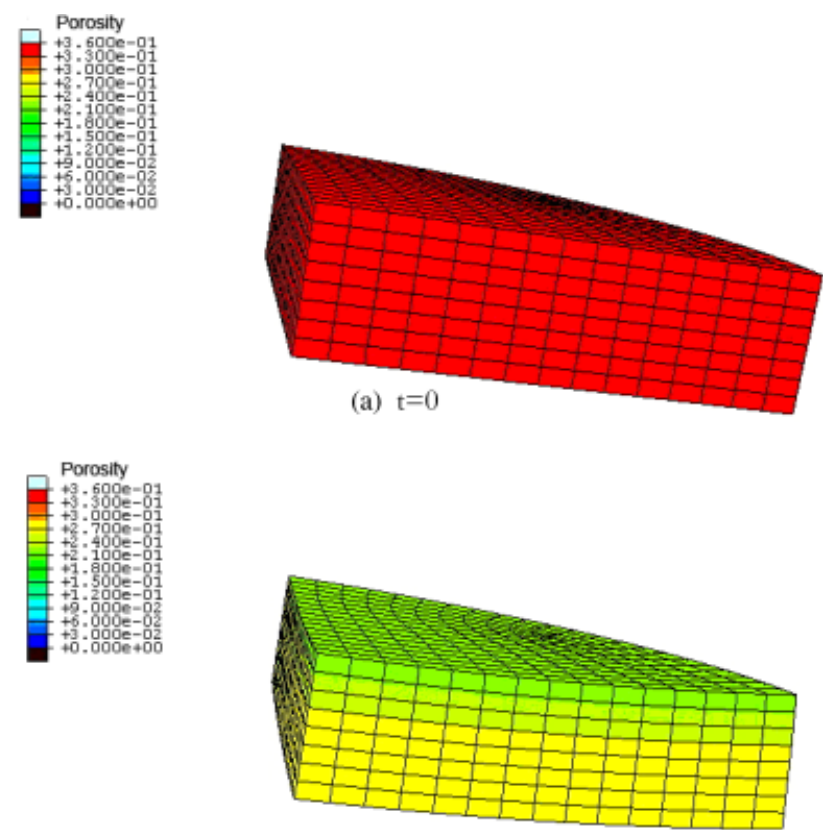

(b) $\mathrm{t}=1800 \mathrm{~s}$
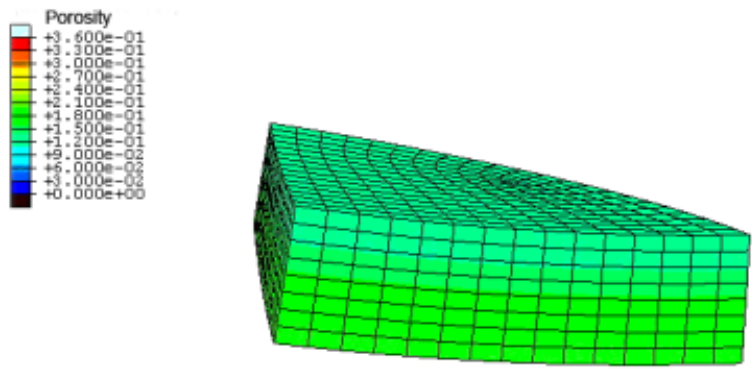

(c) $\mathrm{t}=3600 \mathrm{~s}$

Fig. 2. Functionally graded material results: sintering distortions of an alumina-zirconia functionally graded disk.

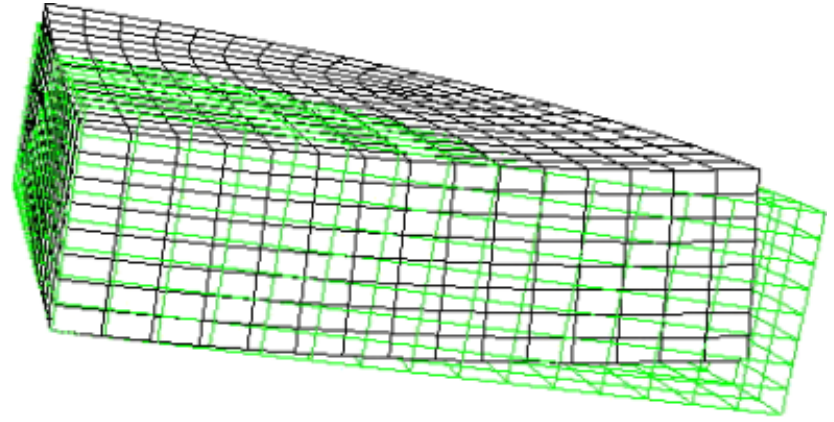

Fig. 3. Shape distortion of an functionally graded material disk during sintering: comparison with the initial shape.

sintering. However, this shrinkage is somewhat impeded for the top layer compared with the bottom one.

The comparison of the shape change predicted by the finite element calculations and the experimental results of a sintered FGM disk (Sample FGM 02, Table II) are represented in Fig. 4 (see Section $\operatorname{III}(2)(B)$ ). In the finite element calculation, the FGM disk is assumed to initially have various porosities along the radial direction, changing from 0.50 to 0.35 from the center to the perimeter of the FGM disk. This assumption is based on averaging of the microscopy image analysis data obtained for all the investigated specimens. The microscopy image analysis has been performed for three different areas located along the radial direction of the diametric planes of the specimens after they have been presintered and sectioned following the postdeposition drying. The chemical composition of the initial specimens before sintering varied along the specimens' heights. The larger porosity in the center can be explained by the constrained (at the substrate interface) boundary conditions of drying. One can see from Fig. 4 that the modeling prediction is very close to the experimentally observed distorted shape.

\section{(5) Modeling Optimization: Solution of Inverse Problem of Sintering of FGM}

Solutions of traditional direct sintering modeling problems predict shape distortions and density evolution during sintering. However, the solution of inverse optimization problems is even more technologically important. In the formulation of the inverse sintering problem, the final shapes of components are known and the initial shapes have to be determined.

Two approaches can be used to solve inverse problems of sintering. The first is to change the sign of sintering stress, which allows the specimen to swell after "inverse sintering." Another approach is to inverse the shape instead of inversing the sintering stresses. Below, we describe both approaches and ultimately use their combination for the optimization of the initial shape of a post-EPD component, which should yield the required final shape and property distribution after sintering.

(A) Sintering Stress Inversion: To solve the inverse sintering problem, it seems natural to consider the "inverse" process of swelling of components from the final to the initial shape under the influence of the pressure $-P_{\mathrm{L}}$. This is the main idea of the approach.

As a result of the calculations, the initial shape corresponding to a certain level of the mean initial density can be readily found, but the initial density will be distributed nonuniformly in the volume. To obtain the initial shape of green bodies with a uniform density distribution, an iterative procedure is used. After the first step of the inverse calculations, the next step is the direct modeling of powder sintering, with the initial shape of the preform taken from the previous step. The initial density is taken to be uniformly distributed throughout the volume. The calculations are carried out up to a density of about $99 \%$. As a result of the calculations, the density distribution in the component is obtained. At the next step, the inverse calculations from the given final shape are used again, but the starting density 


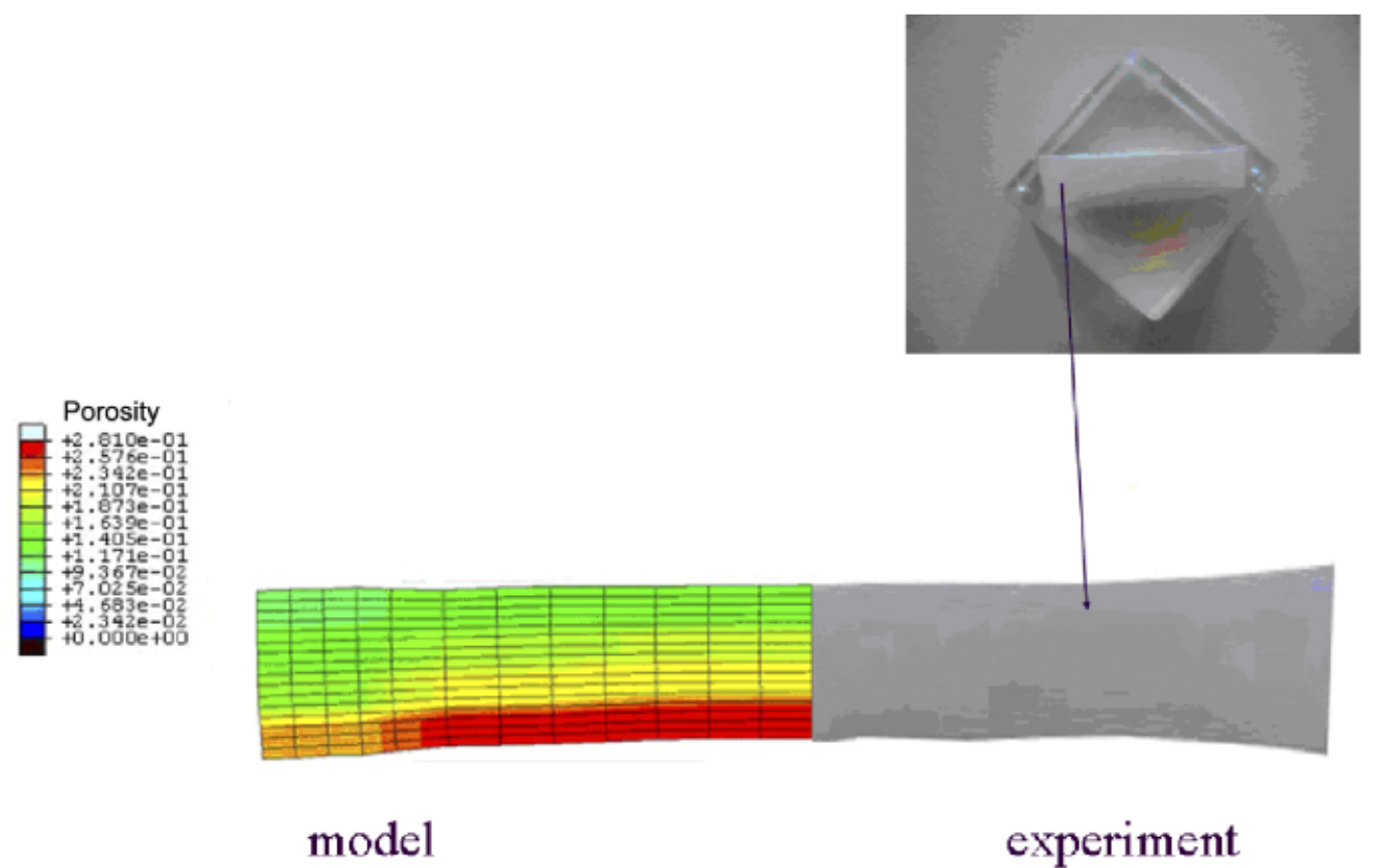

Fig. 4. Comparison of modeling and experimental results on sintering of a functionally graded alumina-zirconia disk.

distribution is taken from the previous direct step. The mapping of density distribution from the distorted to the undistorted final shape can be readily carried out if the same finite element mesh is used for all steps of the iterative procedure without remeshing. In this case, the inherent correspondence is established between the elements of the green body during all stages of the procedure. In such a manner, at the beginning of the inverse step the density of the corresponding element from the foregoing direct step is attributed to every element. The iteration procedure can be repeated until the condition of practical convergence for the initial shape of the component is met. Earlier, this procedure has been used for the prediction of optimum initial shapes of powder components during HIP. ${ }^{31}$ The schematics of this iteration procedure are shown in Fig. 5.
The above-mentioned procedure can be applied only if the sintering stress and the constitutive behavior of the powder body are known. In the present investigation, sintering of preforms made of a mixture of alumina and zirconia is considered. These two powders possess about a 10 times difference in particle sizes. The difference in the grain size is considered to be a main contributor toward the non-uniform sintering of a functionally gradient composite. The sintering stress is sensitive to the powder size and, as a result, in the case of a mixture of powders with different sizes, it becomes a function of the concentrations of the constituents (see Section II (2)).

(B) Inversion of Distorted Shape: This can be realized by an iteration process described in Fig. 6. For each iteration, the calculated shape $S_{\mathrm{i}}$ is compared with the initial shape $S_{\mathrm{o}}$, that is,

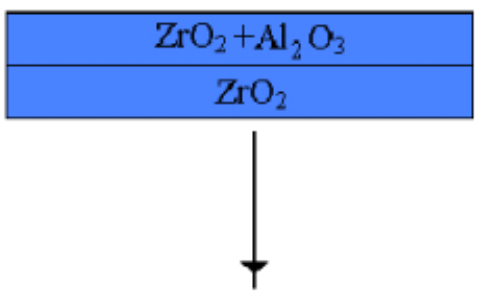

Distorted shape with non-uniform porosity

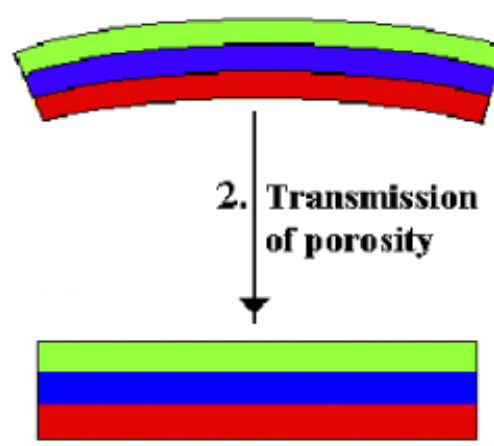

Final shape with non-uniform porosity
Distorted initial shape with uniform porosity

1. Direct

sintering

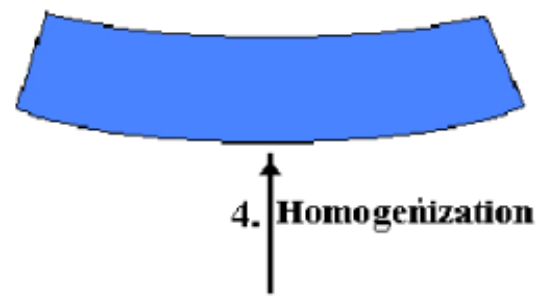

3. Reverse

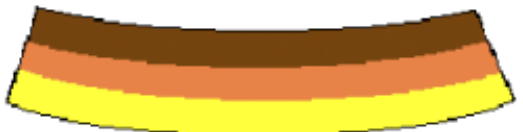

Distorted initial shape with non-uniform porosity

Fig. 5. Schematics of the iteration procedure based on sintering stress inversion. 


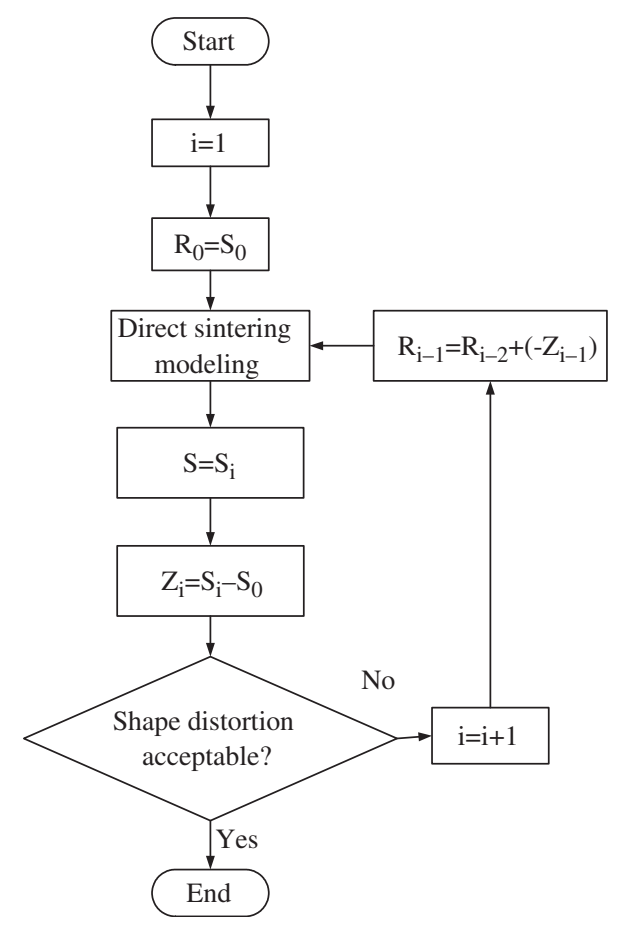

Fig. 6. Iteration process to solve the inverse problem. Initial iteration is conducted using the "negative sintering stress" approach.

the displacement $Z_{\mathrm{i}}$ of every node $i$ is computed. In Fig. 6, $R_{\mathrm{i}}$ corresponds to the initial position of node $i$. The shape distortion factor is used to define the tolerance of the convergence $^{15}$

$$
\begin{aligned}
\Delta= & {\left[1-\left(\frac{h_{0}}{\hat{h}} \cdot \frac{\hat{R}}{R_{0}}\right)^{\operatorname{sgn}\left(\hat{h} / h_{0}-\hat{R} / R_{0}\right)} \exp \left(\frac{\Delta_{R}}{\hat{R}}+\frac{\Delta_{\mathrm{h}}}{\hat{h}}\right)\right] } \\
& \times 100 \%
\end{aligned}
$$

where $h_{0}$ and $R_{0}$ are the initial height and radius, respectively, $\hat{h}$ and $\hat{R}$ are the average height and radius of the distorted specimen

$$
\hat{R}=\frac{1}{n} \sum_{i=1}^{n} R_{i}, \quad \hat{h}=\frac{1}{k} \sum_{i=1}^{k} h_{i}
$$

$\Delta_{\mathrm{h}}$ and $\Delta_{\mathrm{R}}$ are the height and radius standard deviations of the distorted specimen:

$$
\begin{gathered}
\Delta_{R}=\sqrt{\frac{1}{n-1} \sum_{i=1}^{n}\left(R_{i}-\hat{R}\right)^{2}} \\
\Delta_{h}=\sqrt{\frac{1}{k-1} \sum_{i=1}^{k}\left(h_{i}-\hat{h}\right)^{2}}
\end{gathered}
$$

After each iteration, the shape distortion is computed to determine the convergence.

The optimized initial shape after the third iteration, represented in Fig. 7(a), is obtained as a result of the combination of the two above-mentioned approaches. The approaches are integrated in a consecutive manner, when the initial inverse calculation is conducted to obtain the distorted initial shape using the "negative sintering stress" algorithm, and the subsequent direct modeling is conducted after averaging of the nonuniform porosity distribution through each finite element layer's volume. It was assumed that the required final shape had to be cylindrical. The "modeling experiments" at each iteration were then performed starting from the optimized initial shape and, simultaneously, from the adjusted relative densities throughout the finite element mesh. The final modeled sintered FGM disk is shown in Fig. 7(b). It is clear that the final shape is almost identical to the desired cylindrical disk-like shape. The shape distortion factor is $\Delta=0.29 \%$ after sintering (illustrating small deviation from cylindricity). It was found that at the first iteration, the shape converges very quickly to the final shape. During the second and third iterations, the improvements were not significant. Similar results have been obtained in our preliminary investigation based on the "inverse swelling" approach. ${ }^{32}$
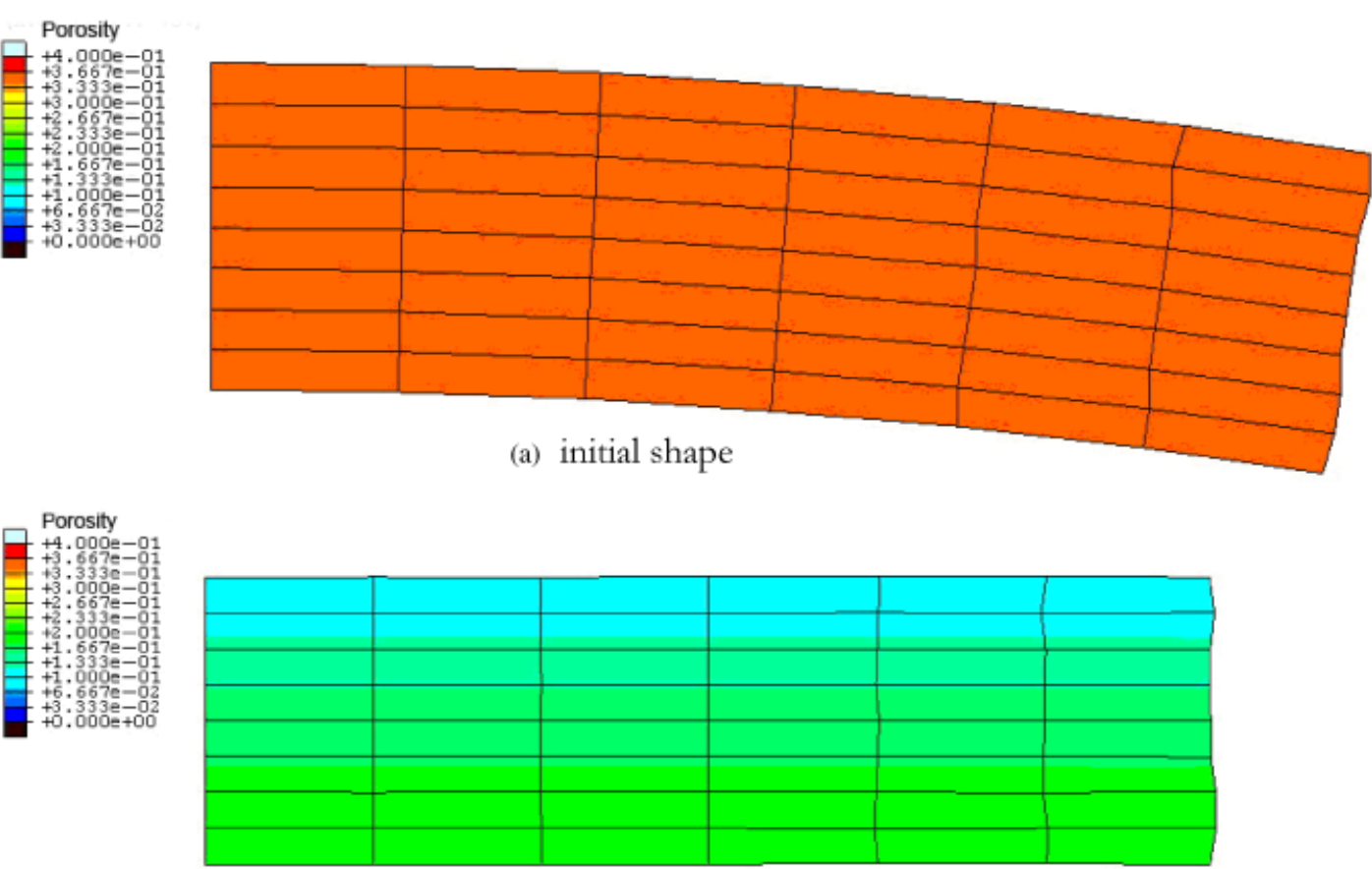

(b) final shape

Fig. 7. Initial shape necessary to obtain the final cylindrical shape optimized by inverse sintering modeling. 


\section{Experimental Procedures}

\section{(1) Electrophoretic Deposition of 3-D FGM}

(A) Materials and Experimental Setup: For the synthesis of cylindrical FGM objects, $\mathrm{Al}_{2} \mathrm{O}_{3}$ (Leco, Augusta, GA, powder series 810-777; average particle size $5.0 \mu \mathrm{m}$ ) and $3 \mathrm{~mol} \%$ $\mathrm{Y}_{2} \mathrm{O}_{3}-\mathrm{ZrO}_{2}$ (Tosoh, Tokyo, Japan, powder TZ-3Y; average particle size $0.5 \mu \mathrm{m}$ ) powders were used. Acetone (Fisher Scientific, Pittsburgh, PA) was used as the suspension medium. $N$-butylamine (Acros, Geel, Belgium, 99.5\%) with 8 vol\% concentration was added to enhance particle charging. In order to obtain an optimal concentration of $N$-butylamine, viscosity measurements were conducted. A Brookfield DV II PRO viscometer (Brookfield Engineering Laboratories, Middleboro, MA) was used. It has a spin head, which can measure both the shear strain rate and shear stress. Because viscosity is sensitive to temperature, in this experiment, the temperature was maintained at $25^{\circ} \mathrm{C}$. To evaluate the optimum concentration of $n$-butylamine, a series of experiments were conducted. $\mathrm{Al}_{2} \mathrm{O}_{3}$ ( $5 \mu \mathrm{m}$, Alcoa A-16 SG, Pittsburgh, PA) was dispersed in acetone with a concentration of $100 \mathrm{~g} / \mathrm{L}$. By adding different amounts of $\mathrm{N}$-butylamine, the viscosity was measured. The viscosity achieved a minimum at about $8 \%$ vol of $N$-butylamine. As mentioned above, this concentration has been used in further experiments.

In some cases, such as when dealing with large particle sizes, chemical additives were not able to suspend particles, and thus stirring was usually adopted. However, it was found by the experiments that excessive stirring sometimes led to particle agglomeration. The suspension was magnetically stirred and then subjected to ultrasonic vibrations (L\&R Manufacturing Company, Q90 Kearny, NJ) to break particle agglomeration. Two stainless-steel pieces were used as electrodes. The EPD experiment was carried out using the setup schematically illustrated in Fig. 8.

(B) EPD of FGMs: Control of the deposition thickness and the composition profile is one of the most important factors to produce 3-D FGM. Two series of experiments were carried out to determine the deposition kinetics for $\mathrm{Al}_{2} \mathrm{O}_{3}$ and $\mathrm{ZrO}_{2}$, respectively. The parameters used in the experiment are listed in Table I. Under a fixed condition (voltage, stirring rate, particle concentration), EPD has been conducted during different time periods. After EPD, the cylindrical deposits were dried in air for $24 \mathrm{~h}$ and then their weight was measured to determine the EPD yield. The experimental results are shown in Fig. 9. The measured deposition kinetics indicates the peak value of the deposition weight; after that, the deposition weight declined. The reason is that as the deposit thickness and weight increase, the adhesion force holding the deposit together cannot compensate the gravity force of the deposit; as a result, some part of the deposit "slips" back to the slurry.

In order to obtain a 3-D FGM, a peristaltic pump was used to add a $\mathrm{ZrO}_{2}$ suspension continuously to the deposition container. Three FGM disks (of 36-mm diameter and 9-mm height) with different composition profiles were deposited using EPD. The experimental regime is listed in Table II.

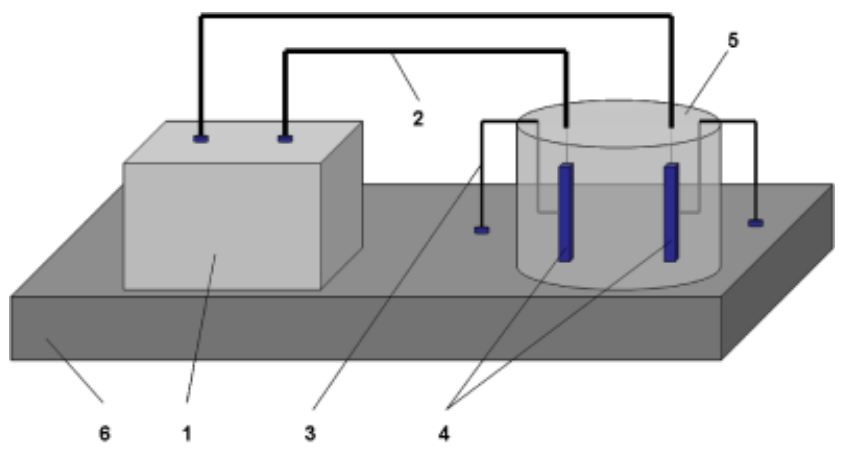

Fig. 8. Schematic illustration of the experimental setup: 1, DC power supply; 2, Leads; 3, Electrode fixture; 4, Electrodes; 5, Suspension container; 6 , Stands.
Table I. Experimental Parameters to Determine $\mathrm{Al}_{2} \mathrm{O}_{3}$ and $\mathrm{ZrO}_{2}$ EPD Kinetics

\begin{tabular}{lc}
\hline Parameter & Value \\
\hline Voltage $(\mathrm{V})$ & 200 \\
Distance between electrodes $(\mathrm{mm})$ & 30 \\
Electrode material & Stainless steel \\
Electrode surface area $\left(\mathrm{mm}^{2}\right)$ & 961 \\
Particle loading $(\mathrm{g} / \mathrm{L})$ & 200 \\
Stirring method & Magnetic stirring
\end{tabular}

EPD, electrophoretic deposition.

For EPD of a 3-D structure, an important problem is cracking. During the drying of a green sample in air, due to the capillary pressure, cracks may be formed. ${ }^{33}$ Adding a binder may increase the strength of the deposits, but it may also increase the adhesion between the electrode and the deposit. As a result, too much binder could be detrimental to crack prevention. The specimens obtained based on the EPD regimes described in Table II were free of cracks (the utilized particle sizes - see Section $\operatorname{III}(1)(A)$-were large enough to prevent excessive capillary pressure build-up).

\section{(2) Sintering: Processing of Disk-Shaped Specimens}

(A) Dilatometry Experiments: Dilatometry experiments were conducted to obtain the sintering constitutive parameters (activation energy in expression (15)) of the composite aluminazirconia powders.

$\mathrm{Al}_{2} \mathrm{O}_{3} / \mathrm{ZrO}_{2}$ composite powders with different concentrations were first baked in a vacuum furnace (Precision Inc., Minneapolis, MN) at $200^{\circ} \mathrm{C}$ for $24 \mathrm{~h}$ to get rid of moisture. After baking, the powders with different concentrations were mixed in a sealed bottle using a rotary blender machine. The compositions of the powder mixtures are listed in Table III.

After mixing of powders, they were cold pressed (up to 50 MPa by a hydraulic press) in a steel rigid die with a diameter of $0.5 \mathrm{in}$. The after-pressing porosity was $54 \%-60 \%$ (which is comparable with the porosity of the specimens obtained by EPD). The dilatometry was conducted using a Theta Industries Dilamatic II SDP dilatometer (Port Washington, NY) with a mechanical push rod and micrometer to measure the shrinkage of specimens. The heating rate was $10^{\circ} \mathrm{C} / \mathrm{min}$. After initially heating up to $1500^{\circ} \mathrm{C}$, the specimens were sintered for $4 \mathrm{~h}$. The shrinkage curve was recorded for each specimen.

After sintering, the final length of each specimen was measured using a digital caliper. The porosity was measured using the Archimedes method. The experimental results are plotted in Fig. 10. It can be seen from the results that the activation energy is very close to that measured by Raj (see Eq. (16)). The value of $Q(700 \mathrm{~kJ} / \mathrm{mol})$ has been used in the calculations described in Section II (3).

Here, it should be noted that for linear-viscous sintering models, it is sufficient to know the specific time of sintering (in

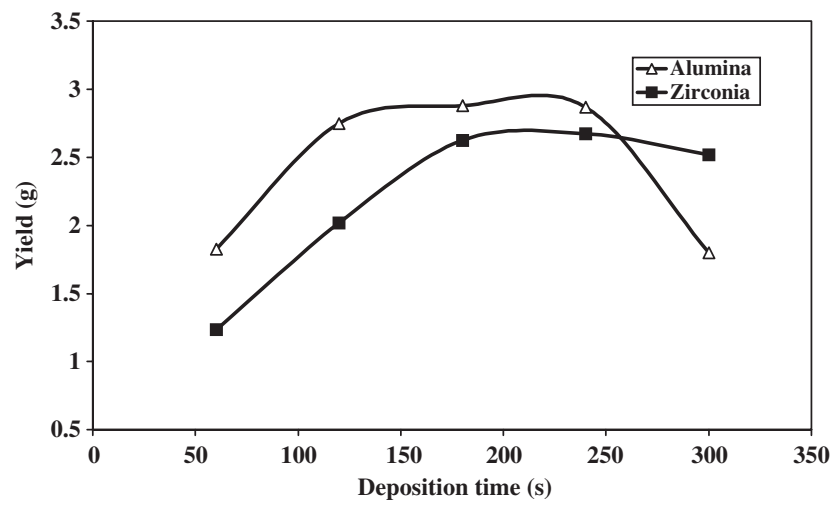

Fig. 9. Deposition yields vs. time of $\mathrm{Al}_{2} \mathrm{O}_{3}$ and $\mathrm{ZrO}_{2}$ powders. 
Table II. EPD Condition for FGM Green Specimen $(180 \mathrm{~s}, 200 \mathrm{~V})$

\begin{tabular}{lll}
\hline Number & \multicolumn{1}{c}{ Starting suspension } & Adding suspension \\
\hline FGM01 & $120 \mathrm{~mL} \mathrm{solution}$ & $30 \mathrm{~mL}$ solution \\
& $+24 \mathrm{~g} \mathrm{Al}_{2} \mathrm{O}_{3}$ & $+12 \mathrm{~g} \mathrm{ZrO}_{2}$ \\
FGM02 & Residual suspension & $20 \mathrm{~mL} \mathrm{solution}$ \\
& from FGM01 & $+10 \mathrm{~g} \mathrm{ZrO}_{2}$ \\
FGM03 & Residual suspension & $20 \mathrm{~mL} \mathrm{solution}$ \\
& from FGM02 & $+10 \mathrm{~g} \mathrm{ZrO}_{2}$ \\
\hline
\end{tabular}

EPD, electrophoretic deposition.

Table III. Composition of $\mathrm{Al}_{2} \mathrm{O}_{3} / \mathrm{ZrO}_{2}$ Powder Mixtures for Dilatometry

\begin{tabular}{lccc}
\hline $\begin{array}{l}\text { Specimen } \\
\text { number }\end{array}$ & $\begin{array}{c}\text { Volume } \\
\text { concentration } \\
\text { of } \mathrm{ZrO}_{2}(\%)\end{array}$ & $\begin{array}{c}\text { Volume } \\
\text { concentration } \\
\text { of } \mathrm{Al}_{2} \mathrm{O}_{3}(\%)\end{array}$ & $\begin{array}{c}\text { Weight of specimen } \\
(\mathrm{g})\end{array}$ \\
\hline 1 & 50 & 50 & 4.317 \\
2 & 25 & 75 & 4.230 \\
3 & 75 & 25 & 4.720 \\
4 & 90 & 10 & 4.424 \\
5 & 10 & 90 & 4.32 \\
\hline
\end{tabular}

this case it is $\tau_{\mathrm{s}}=\int_{0}^{t}\left(\alpha / A \eta_{0}\right) \mathrm{d} t$, where surface tension $\alpha$, shear viscosity $\eta_{0}$, and shrinkage rate pre-exponential factor $A$ are from Eqs. (14), (20), and (15), respectively) to determine the shrinkage rate directly. It is this specific feature of linear-viscous sintering models that has been utilized in the present work when determining constitutive parameters of alumina-zirconia powder mixtures based on the inverse regression of the results of dilatometry tests conducted for specimens with different concentrations of alumina and zirconia.

It should be noted that the variation of sintering stress in a composite powder is attributable to both variations in particle sizes and variations in specific surface energy. The latter can be considered to be a macroscopic average throughout the entire volume of the mixed powders, so that all the differences in the sintering stress are due to the varying particle sizes. Implicitly, this information is included in the specific time of sintering (see Eqs. (14), (15), and (20)):

$$
\tau_{\mathrm{s}}=\int_{0}^{t} \frac{\alpha}{A \eta_{0}} \mathrm{~d} t=2 \int_{0}^{t} \frac{\exp \left(-Q / R_{\mathrm{g}} T\right)}{T} \frac{f(\rho)}{R_{\mathrm{p}}^{4}} \frac{\psi}{\bar{P}_{\mathrm{L}}} \mathrm{d} t
$$

where $\bar{P}_{\mathrm{L}}=P_{\mathrm{L}} / \alpha$. Thus, one can determine the ratio $\alpha / A \eta_{0}$ from the dilatometry data and utilize it in finite-element calculations (see Sections $\mathrm{II}(4)$, and $\operatorname{III}(3)$ ).

(B) Sintering of $\mathrm{Al}_{2} \mathrm{O}_{3} / \mathrm{ZrO}_{2} \mathrm{FGMs}_{\mathrm{S}}$ : Sintering was conducted in air in a box furnace (Thermolyne 46200, Barnstead International, Dubuque, IA) for $4 \mathrm{~h}$. The maximum temperature

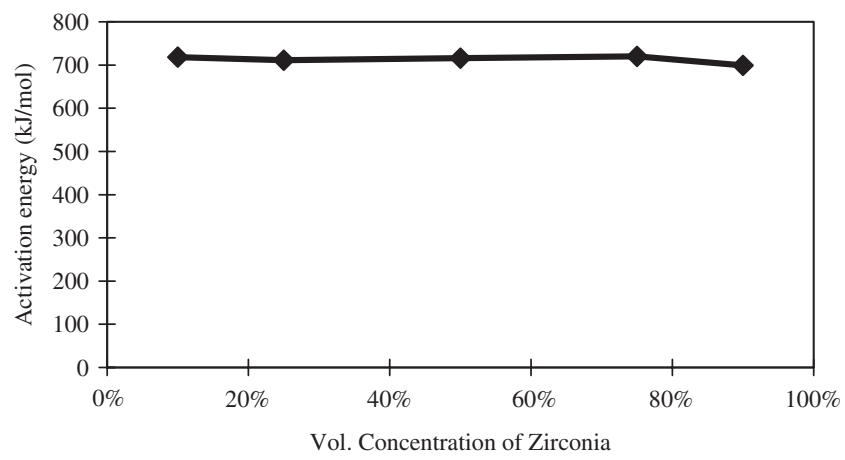

Fig. 10. Activation energy for sintering densification in accordance with Eq. (15) versus volume concentration of $\mathrm{ZrO}_{2}$.
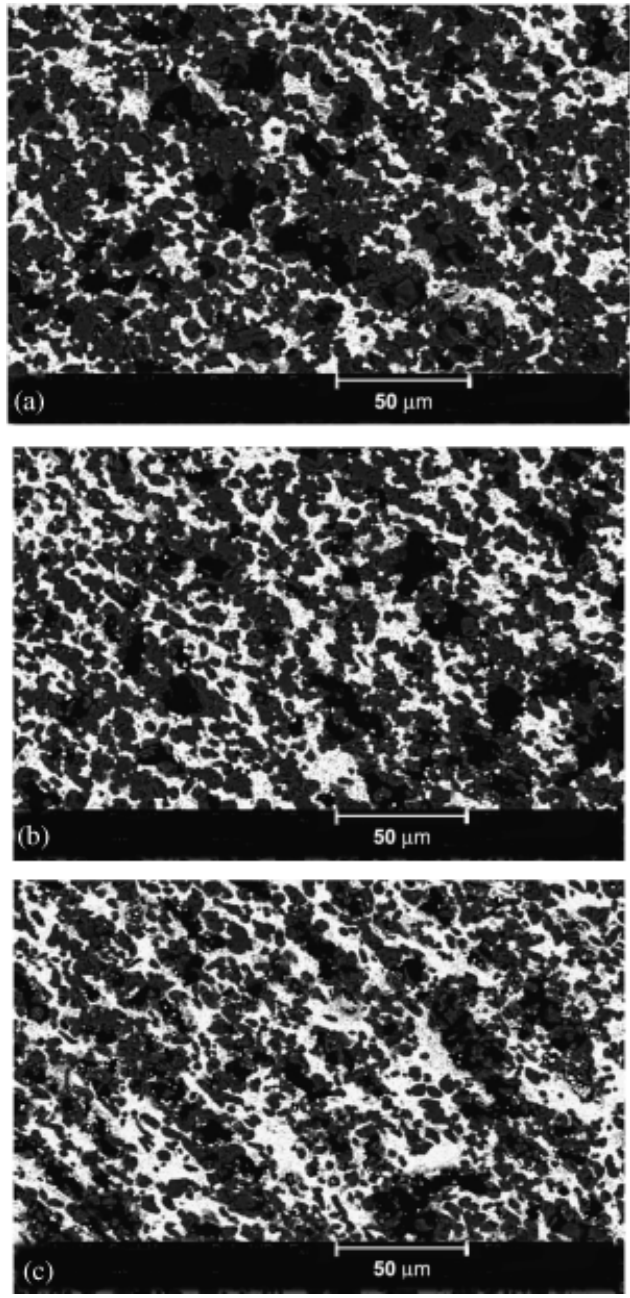

Fig. 11. Microstructure of disk-shaped FGM (in planes perpendicular to the specimen's axis): (a) $\mathrm{Al}_{2} \mathrm{O}_{3}$-rich layer; (b) Intermediate layer; (c) $\mathrm{ZrO}_{2}$-rich layer.

was $1500^{\circ} \mathrm{C}$ (with heating ramp of $5^{\circ} \mathrm{C} / \mathrm{min}$ ). After sintering, the samples were characterized by SEM. Figure 4 shows one of the distorted FGM disks after sintering (FGM02, see Table II). The final relative density of the disk was $99 \%$ as measured by the Archimedes method. The shrinkage along the diameter direction is $27 \%$. Both the top and the bottom of the disk warped toward the center. However, the bottom warpage was more pronounced than that of the top.

Figure 11 shows the microstructure of one of the sintered FGM samples. The white area indicates $\mathrm{ZrO}_{2}$ the gray area indicates $\mathrm{Al}_{2} \mathrm{O}_{3}$, and the black areas indicates pores. From Figs. 11(a)-(c), it can be seen that the concentration of $\mathrm{ZrO}_{2}$ changes throughout the specimen. The transition of $\mathrm{ZrO}_{2}$ concentration is smooth (quasi-linear $\sim 15 \%-85 \%$ ) across the entire thickness of the disk. Figure 12 shows the necking between alumina and zirconia particles. It can clearly be seen that the bonding is well established after sintering between particles of $\mathrm{Al}_{2} \mathrm{O}_{3}$ and $\mathrm{ZrO}_{2}$. The grain growth was very limited during sintering (the final average grain sizes were close to 5 and $0.5 \mu \mathrm{m}$ for alumina and zirconia, respectively).

Shape distortions during sintering have been observed and compared with model predictions (see Fig. 4). As has been earlier mentioned (Section II(4)) the model and experimental results agree quite satisfactorily.

\section{(3) EPD-Sintering Net-Shape Optimization}

(A) Fabrication of the Optimized Initial Shape by EPD: The FEM continuum modeling results of Section II(4) indicate what the initial shape should be in order to pro- 


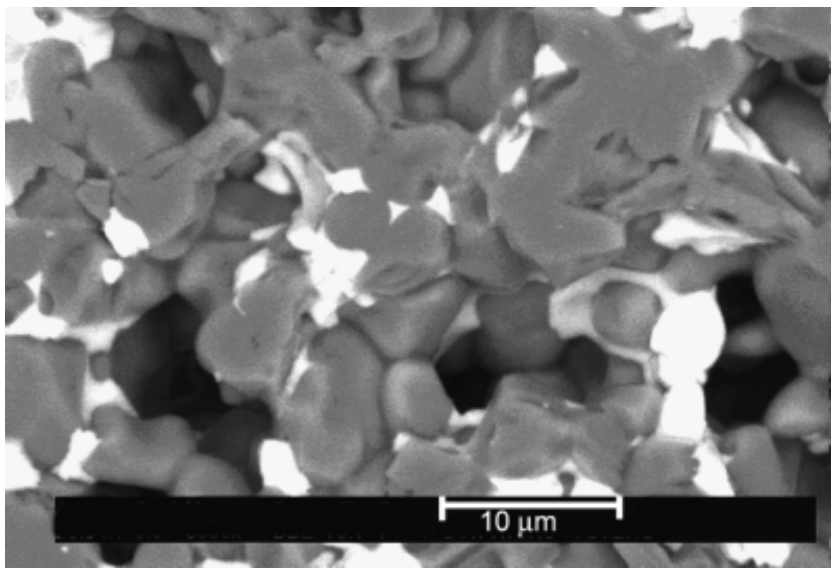

Fig. 12. Contact between $\mathrm{Al}_{2} \mathrm{O}_{3}$ (gray) and $\mathrm{ZrO}_{2}$ (white) particles.

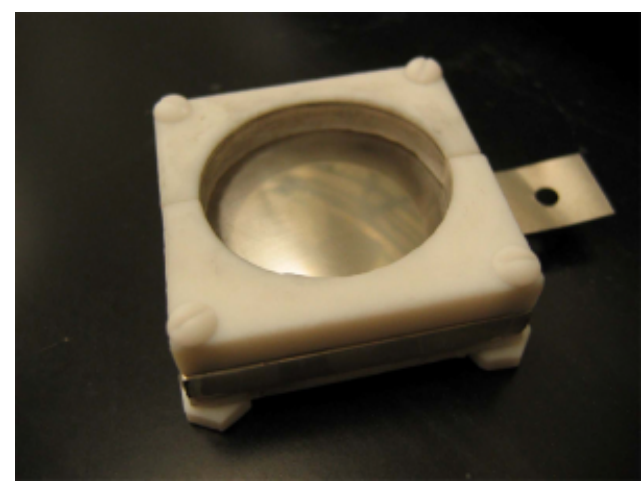

Fig. 13. Electrode assembly for electrophoretic deposition of the optimized initial shape.

duce the final desired shape after sintering. In this section, the problem of the fabrication by EPD of such an optimized initial green specimen is addressed. The experimental part together with the theoretical part provides a novel systematic solution to the near-net-shaping problem of FGM sintering.

In previous sections, it has been shown that in order to obtain a flat disk $\mathrm{Al}_{2} \mathrm{O}_{3} / \mathrm{ZrO}_{2}$ FGM after sintering, a distorted initial green shape has to be produced. The shape of a deposit in EPD follows the shape of the deposition electrode. Realizing this fact, an electrode, which has the same configuration as the one predicted by sintering inverse modeling results, has been designed using CAD/CAM. The electrode was made from stainless steel. The assembly of the electrode is shown in Fig. 13. The bottom curve of the electrode was approximated by an arc using three points on the curve as interpolation points. Then, the interpolated arc shape was input into 3-D CAD modeling tools (SolidWorks, Concord, MA). After the 3-D model was built, it was transferred into CAM to convert the CAD to an actual component.

In order to deposit materials only in the desired area, the electrode was wrapped by plastic film except at the deposition area.

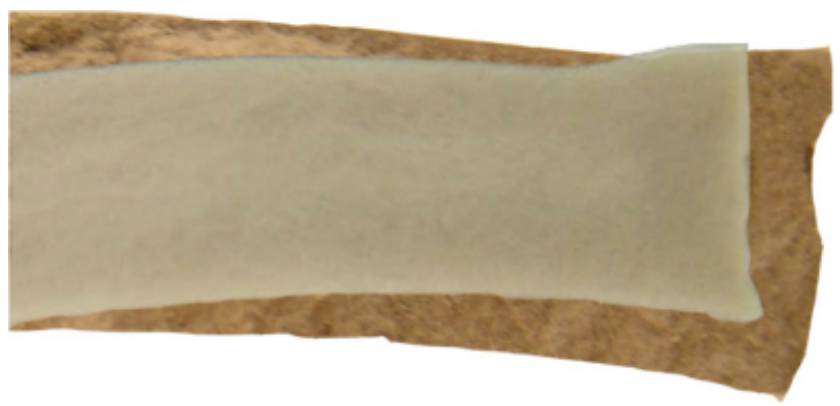

Fig. 14. Comparison between a green specimen and a sintered specimen.

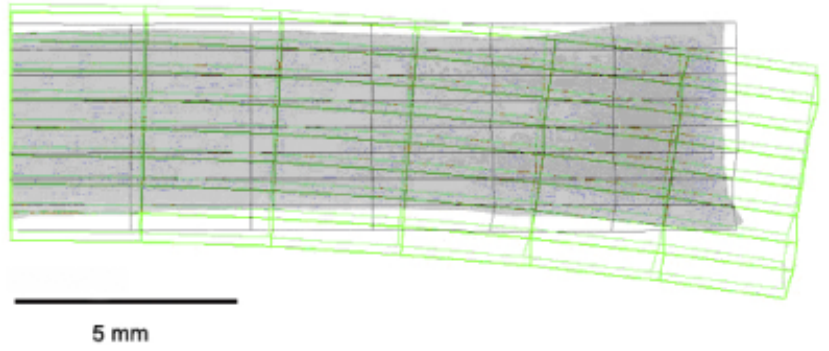

Fig. 15. Comparison of the sintered "inverse" specimen with functionally graded material prediction.

The four screws (see Fig. 13) were made of teflon, which prevented them from attracting particles and influencing the electric field in the suspension.

The materials used in the experiments were $\mathrm{Al}_{2} \mathrm{O}_{3}$ and $\mathrm{ZrO}_{2}$. The deposition scheme is the same as the one summarized in Table II. After deposition, the specimen was removed from the electrode and dried in air for $24 \mathrm{~h}$. Figure 14 shows an FGM disk deposited by EPD with the designed shape determined based on inverse modeling (see Section II $(5))$ ). It can be seen from the picture that the deposited shape was a distorted shape which was the initial shape predicted by the inverse FEM modeling of sintering (Section II $(5)$ ). This specimen was then sintered in a box furnace (Thermolyne 46200) in air at $1500^{\circ} \mathrm{C}$ for $4 \mathrm{~h}$.

(B) Comparison of the Solution of the Inverse Problem of Sintering With the Experimental Results: After sintering, the specimens were cross sectioned. Figure 14 shows the comparison between the green specimen (initial shape obtained by EPD) and the sintered specimen. The gray shape is the sintered specimen, while the brown one indicates the green specimen. The comparison indicates that the distorted initial shape becomes more "flat" after sintering, as predicted by FEM continuum modeling.

The second comparison involves the sintered "inverse" specimen and the sintering FEM prediction results, as shown in Fig. 15. The green wire frame indicates the initial shape predicted by FEM, the gray wire frames indicate the two consecutive shapes after sintering predicted by FEM iterations, while the gray solid shape indicates the shape of the sintered FGM specimen. The comparison indicates that the sintering distortion of the "inverse" designed initial shape agrees with that of the FEM modeling results very well.

The deviation of the modeling results from the experimental data indicates the necessity of the introduction of other parameters into the model. For example, grain growth and other dynamic effects are not taken into account in the model. Other parameters such as particle agglomeration may also influence the results.

It should also be noted that during drying after EPD, the specimen also undergoes shrinkages because of the evaporation of water. Therefore, the specimen was "predistorted" before sintering. This phenomenon also exists in all drying-related powder-processing procedures, such as slip casting. The distortion caused by drying may also contribute to the final shape change after sintering.

\section{Conclusions}

A model of sintering capable of describing the densification of FGMs has been developed. The model has been used for the finite element solution of the direct (the predictions of sintering distortions and density evolution) and inverse (the optimization of the initial shape of a functionally graded green specimen that yields the required final shape after sintering process) sintering problems. The inverse solution is based on a special iteration procedure that combines the adjustment of relative density throughout the finite element mesh and the inversion of sintering displacements. Both the direct and inverse solutions agree 
well with the experimental data on the sintering of alumina-zirconia functionally graded composites. $\mathrm{Al}_{2} \mathrm{O}_{3} / \mathrm{ZrO}_{2}$ 3-D FGM structures were successfully deposited by the EPD technique. Green electrophoretically deposited specimens were densified by sintering. The sintered specimens were characterized by SEM and clearly show the graded structure with limited grain growth. A perfect net shaping still remains a difficult-to-achieve objective; the results presented should be considered as one of the first steps in this direction. Model improvements by taking into consideration the omitted factors and phenomena (see Section $\operatorname{III}(3)(B))$ as well as further modeling-based fine tailoring of the material structure should hopefully render technologically acceptable net-shaping capabilities of EPD-sintering processing sequence.

\section{References}

${ }^{1}$ P. Sarkar and P. S. Nicholson, "Electrophoretic Deposition (EPD): Mechanisms, Kinetics, and Application to Ceramics," J. Am. Ceram. Soc., 79 [8] 1987-2002 (1996).

${ }^{2}$ P. Sarkar, P. S. Nicholson, and X. Huang, "Zirconia-Alumina Functionally Gradiented Composites by Electrophoretic Deposition Techniques," J. Am. Ceram. Soc., 76 [4] 1055-6 (1993).

${ }^{3}$ I. Zhitomirsky, "Cathodic Electrodeposition of Ceramic and Organoceramic Materials. Fundamental Aspects," Adv. Colloid Interface Sci., 97 [1-3] 279-317 (2002)

${ }^{4}$ A. R. Boccaccini and I. Zhitomirsky, "Application of Electrophoretic and Electrolytic Deposition Techniques in Ceramics Processing," Curr. Opin. Solid State Mater. Sci., 6 [3] 251-60 (2002).

${ }^{5}$ S. Put, J. Vleugels, G. Anne, and O. Van Der Biest, "Electrophoretic Deposition Fundamentals and Applications," The Electrochem. Soc. Proc., PV2002-21, 198-205 (2002).

${ }^{6}$ S. Put, J. Vleugels, and O. Van Der Biest, "Gradient Profile Prediction in Functionally Graded Materials Processed by Electrophoretic Deposition," Acta Mater., 51, 20, 6303-17 (2003).

${ }^{7}$ X. Wang, J. Ma, A. Maximenko, E. A. Olevsky, M. B. Stern, and B. M. Guenin, "Sequential Deposition of Copper/Alumina Composites," J. Mater. Sci., 40 [18] 4963-5 (2005).

${ }^{8}$ E. A. Olevsky, X. Wang, J. Ma, A. Maximenko, and M. B. Stern, "Sequential Deposition and Electroforming of Metal/Ceramic Composites for Thermal Management Applications," Surf. Eng., 23, 12-7 (2007).

${ }^{9}$ V. Skorohod, E. Olevsky, and M. Shtern, "Continuum Theory of Sintering of the Porous Bodies: Model and Application," Int. J. Sci. Sinter., 23 [2] 79-91 (1991).

${ }^{10}$ E. Olevsky, H. J. Dudek, and W. A. Kaysser, "HIPing Conditions for Processing of Metal Matrix Composites Using Continuum Theory for Sintering I. Theoretical Analysis," Acta Met. Mater., 44, 707-13 (1996).

${ }^{11}$ E. Olevsky, H. J. Dudek, and W. A. Kaysser, "HIPing Conditions for Processing of Metal Matrix Composites Using Continuum Theory for Sintering II Application to Fibre Reinforced Titanum Alloys," Acta Met. Mater., 44, 715-24 (1996)
${ }^{12}$ E. Olevsky, V. Skorohod, and G. Petzow, "Densification by Sintering Incorporating Phase Transformations," Scripta Mater., 37, 635-43 (1997).

${ }^{13}$ E. Olevsky, "Theory of Sintering: From Discrete to Continuum," Mater. Sci. Eng. R, 23, 41-100 (1998).

${ }^{14}$ E. A. Olevsky and R. M. German, "Effect of Gravity on Dimensional Change During Sintering, I. Shrinkage Anisotropy," Acta Mater., 48, 1153-66 (2000)

${ }^{15}$ E. A. Olevsky and R. M. German, "Effect of Gravity on Dimensional Change During Sintering, II. Shape Distortion," Acta Mater., 48, 1167-80 (2000)

${ }^{16}$ E. A. Olevsky and A. Molinari, "Instability of Sintering of Porous Bodies," Int. J. Plasticity, 16, 1-37 (2000).

${ }^{17}$ M. Braginsky, V. Tikare, and E. Olevsky, "Numerical Simulation of Solid State Sintering," Int. J. Solids and Struc., 42, 621-36 (2005).

${ }^{18}$ E. A. Olevsky, J. C. LaSalvia, J. Ma, and M. A. Meyers, "Densification of Porous Bodies in a Granular Pressure-Transmitting Medium," Acta Materialia, 55, 1351-66 (2007).

${ }^{19}$ E. Olevsky, V. Tikare, and T. Garino, "Multi-Scale Modeling of Sintering-A Review," J. Am. Ceram. Soc., 89 [6] 1914-22 (2006).

${ }^{20}$ R. M. McMeeking and L. T. Kuhn, "A Diffusional Creep Law for Powder Compacts," Acta Metall. Mater., 40, 961-9 (1992).

${ }^{21}$ D. Bouvard and R. M. McMeeking, "Deformation of Interparticle Necks by Diffusion-Controlled Creep,” J. Am. Ceram. Soc., 79, 666-72 (1996).

${ }^{22}$ J. Pan, H. Le, S. Kucherenko, and J. A. Yeomans, "A Model for the Sintering of Spherical Particles of Different Sizes by Solid State Diffusion," Acta Mater., 46, 4671-90 (1998).

${ }^{23} \mathrm{M}$. Suzuki and T. Oshima, "Estimation of the Co-Ordination Number in a Multicomponent Mixture of Spheres," Powder Technol., 36 [2] 181-8 (1983)

${ }^{24}$ J. Wang and R. Raj, "Activation Energy for the Sintering of Two-Phase Alumina/Zirconia Ceramics," J. Am. Ceram. Soc., 74, 1959-63 (1991).

${ }^{25}$ V. Tikare, M. Braginsky, and E. A. Olevsky, "Numerical Simulation of SolidState Sintering: I, Sintering of Three Particles," J. Am. Ceram. Soc., 86, 49-53 (2003).

${ }^{26}$ Z. Z. Du and A. C. F. Cocks, "Constitutive Models for the Sintering of Ceramic Components 2. Sintering of Inhomogeneous Bodies," Acta Met. Mater., 40 [8] 1981-94 (1992).

${ }^{27}$ T. Kraft, H. Riedel, P. Stingl, and F. Wittig, "Finite Element Simulation of Die Pressing and Sintering," Adv. Eng. Mater., 1 [2] 107-9 (1999).

${ }^{28}$ D. Bouvard, P. Doremus, O. Gillia, and V. Bonnefoy, "Finite Element Simulation of Compaction and Sintering of Ceramic Powders," Key Eng. Mater., 206-2, 243-8 (2002).

${ }^{29}$ M. W. Reiterer, K. G. Ewsuk, and J. G. Arguello, “An Arrhenius-Type Viscosity Function to Model Sintering Using the Skorohod-Olevsky Viscous Sintering Model within a Finite-Element Code," J. Am. Ceram. Soc., 89 [6] 1930-5 (2006).

${ }^{30}$ S. E. Schoenberg, D. J. Green, A. E. Segall, G. L. Messing, A. S. Grader, and P. M. Halleck, "Stresses and Distortion Due to Green Density Gradients During Densification," J. Am. Ceram. Soc., 89 [10] 3027-33 (2006).

${ }^{31}$ E. Olevsky, A. Maximenko, and Y. Ivlev, "Shape Distortion Under Isostatic Pressing," Mater. Sci. Lett., 16, 1270-3 (1997).

${ }^{32}$ A. L. Maximenko, O. Van Der Biest, and E. A. Olevsky, "Prediction of Initial Shape of Functionally Graded Ceramic Pre-Forms for Near-Net-Shape Sintering," Sci. Sintering, 35, 5-12 (2003).

${ }^{33}$ G. W. Scherer, "Theory of Drying," J. Am. Ceram. Soc., 73 [1] 3-14 (1990). 